\title{
19. BRITTLE-DUCTILE SHEAR ZONES IN SLOPE SEDIMENTS OFF GUATEMALA, SITES 568 AND 569, DEEP SEA DRILLING PROJECT LEG 841
}

\author{
Roger Helm and Axel Vollbrecht, Geologisches Institut, Ruhr-Universität Bochum²
}

\begin{abstract}
Zones of en-echelon veins in consolidated muds from Sites 568 and 569 were investigated for structural features and mineralogy. Comparison with experimental data suggests that the veins developed in shear zones as one set of Riedelshears with a dilatational component, reflecting a brittle-ductile behavior of the sediment. The vein filling contains the same clay minerals as does the adjacent sediment (smectite, kaolinite). The microfabric of the vein filling is characterized by fine-grained, closely packed aggregates of clay flakes that form in a strong preferred orientation parallel to the vein boundaries. The geometry and the orientation of the shear zones locally occurring in conjugate sets indicates a coaxial progressive deformation with a vertical direction of maximum finite shortening. The shear zones are the result of the overburden pressure in a slope position, buckling related to subduction-driven processes, or regional-scale slumping.
\end{abstract}

\section{INTRODUCTION}

Different types of veinlike structures filled with a finegrained dark material are a common feature in deep-sea drill cores of partly consolidated hemipelagic muds. Most of these structures can be related to natural rather than drilling-induced deformations, because their spatial distribution and their symmetrical arrangement show no distinct geometrical relationship to the core barrel. Nevertheless, a slight overprinting by drill-induced deformation has to be taken into account (criteria to distinguish between natural and artificial structures were compiled by the Shipboard Scientific Party of Leg 56, 57, 1980; see Appendixes in Arthur, Carson, and von Huene, 1980, and in Dengo, 1982). The main point of discussion is to identify to what extent the development of the different types of veins is governed by tectonic stresses, overburden and pore pressures, sedimentary (primary) structures, diagenetic processes, or some combination of these. A special problem is whether the finegrained vein fillings are mechanically segregated from the surrounding sediment or chemically precipitated from the pore fluid.

This report deals with en-echelon veins in MiocenePliocene hemipelagic muds from a sub-bottom depth of 200 to $400 \mathrm{~m}$ on the landward slope of the Middle America Trench off Guatemala (Holes 568, 569, 569A), for which, according to the above-mentioned criteria, a drill-induced origin can be excluded. Similar veins have been recently described in detail by Arthur, Carson, and von Huene (1980), Cowan (1982), Dengo (1982), and Ogawa and Miyata (this volume). Our study yields further information on macro- and microstructures and the mineralogical composition of the vein-filling material. Our discussion of the origin and further development of

\footnotetext{
${ }^{1}$ von Huene, R., Aubouin, J., et al., Init. Repts. DSDP, 84: Washington (U.S. Govt. Printing Office).

2 Address: Geologisches Institut, Ruhr-Universität Bochum, Universitătsstrasse 150, D4630 Bochum, West Germany.
}

these vein structures is based on geometrical characteristics and on data from analogous experiments.

\section{MACROSCOPIC FEATURES}

In wet drill cores the veins appear as thin, dark-colored structures penetrating the relatively lighter sediments, which can be generally described as consolidated mudstones with a considerable content of siliceous tests. The distinct color contrast, however, diminishes as the sample dries out.

Different angles of intersection between veins and core cuts as well as interference of two or more generations of veins result in rather complex anastomosing fracture patterns. Thus the following brief description only holds for single sets of veins in a section approximately normal to their strike. Other more complex patterns will be treated later in the context of kinematical aspects of the origin and further development of these en-echelon veins.

The most striking feature of the veins is their en-echelon arrangement in zones or bands of different width that traverse straight across the core. Within each zone, the lengths and spacing of the veins are more or less constant. Abrupt changes occur only in areas where the zones intersect distinct sedimentary inhomogeneities (e.g., clasts or bioturbate structures; see Fig. 1). The lengths and spacing between veins appear to be related, because narrow zones usually consist of closely spaced veins, whereas broad zones consist of widely spaced veins. A distance-to-length ratio of at least 3 to 5 seems to be characteristic.

Individual veins are generally less than $1 \mathrm{~mm}$ across in the central regions and decrease in thickness toward the ends, where the vein often parts to form two or more branches. Long veins are commonly sigmoidal, and short veins tend to be straight, as shown in the example in Figure 2 . In short veins the ends are typically inclined at high angles (about $80^{\circ}$ ) to the zone boundaries. In sigmoidally curved veins the angle between the vein and the boundary continuously increases toward the central 


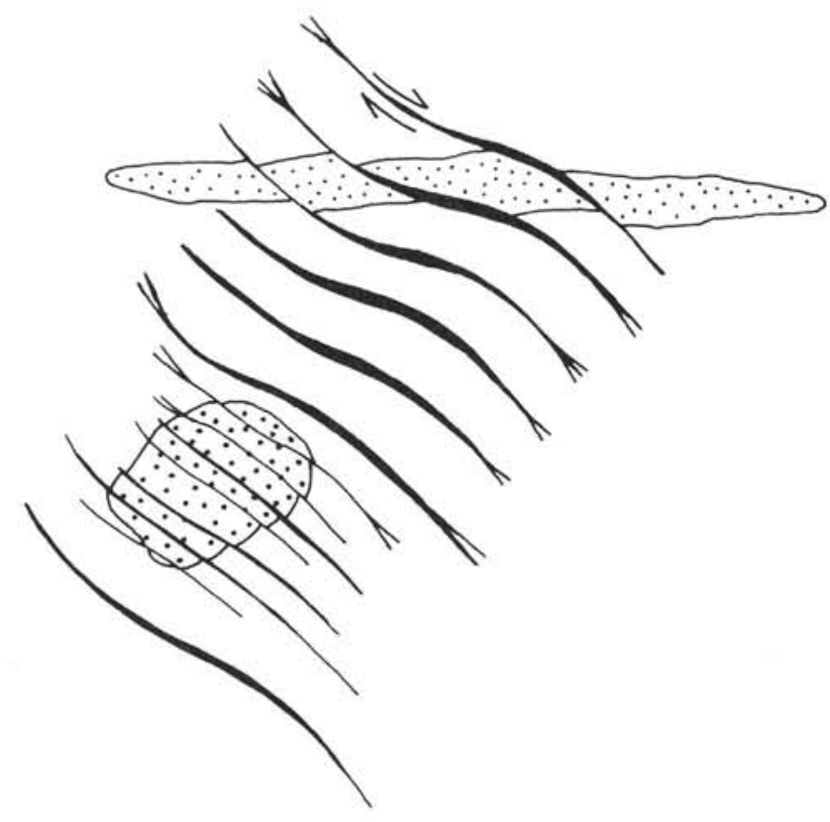

Figure 1. Zone of en-echelon veins. Schematic sketch of macroscopic characteristics, compiled from observations of different core cuts (heavy-dotted area: distinct sedimentary inhomogeneity; light-dotted area: weak sedimentary inhomogeneity).

part of the band. In some cases this angle exceeds $90^{\circ}$. Where strain markers are present (earlier-formed fractures or primary structures) a vein-parallel shear displacement locally up to a few millimeters is detectable and the sense of shear is the same for all veins of the same zone (Fig. 1).

In the core samples used for this investigation, the mudstones exhibit only minor sedimentary structures and generally lack bedding planes. Consequently it is not possible to ascertain whether the orientation of either the veins or the zone boundaries is influenced by primary structures as has been reported from other sites where, for example, zones strictly parallel to the bedding seem to be common (e.g., Cowan, 1982).

\section{MICROSCOPIC FEATURES}

To get information about the composition and microfabric of the dark-colored vein filling, a fresh surface of break across a zone of en-echelon veins was examined by scanning electron microscopy. For better tracing, some reference points were fixed on the still unspattered surface on which the veins are best visible because of their dark color. At low magnification the veins are almost unrecognizable (Fig. 3A). Some appear in higher relief than the matrix material, suggesting slight differences in the mechanical properties between the veins and the surrounding sediment. At higher magnifications a distinct compositional and microstructural contrast between sediment and veins becomes obvious.

At microscopic scale the mudstone appears to be a porous framework of platy phyllosilicates in which abundant fossil debris is embedded. The phyllosilicates and fossil debris generally have a random orientation (Fig. $3 \mathrm{~B})$, and the inter-particle pore space is high. Locally in

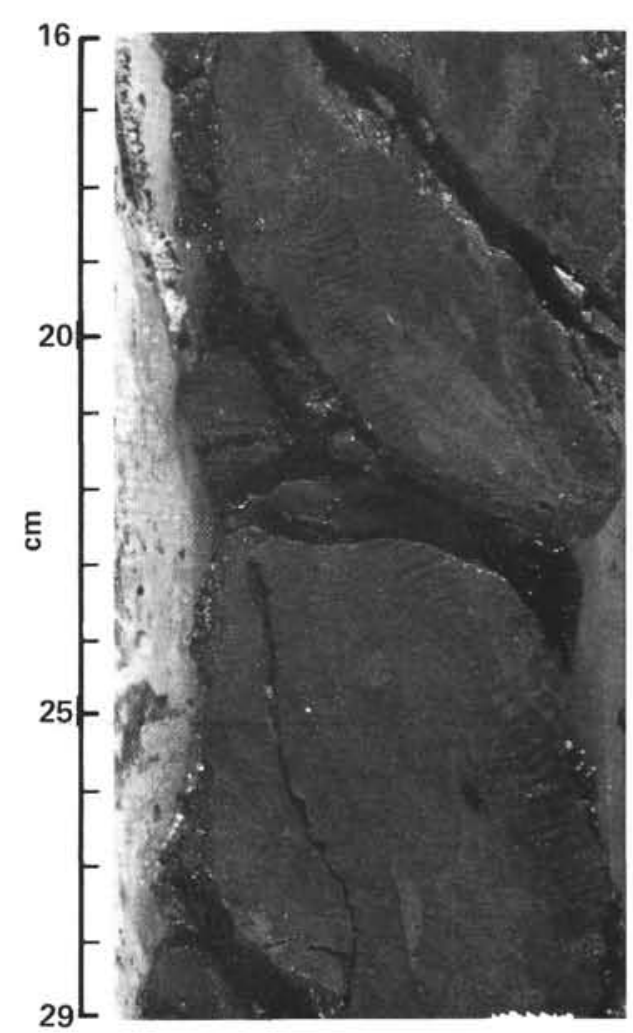

Figure 2. Zone of short, straight, en-echelon veins (Sample 568-42-7, $16-29 \mathrm{~cm})$.

phyllosilicate-rich areas, a parallel orientation of platy grains (Fig. 3C) produces thin layers of lower porosity and higher density. The grain size of both phyllosilicates and fossil debris varies in a wide range, with estimated maximum and average diameters of about $50 \mu \mathrm{m}$ and 10 $\mu \mathrm{m}$, respectively.

In contrast to the sediment, the vein filling consists almost entirely of finer-grained platy phyllosilicates with strong preferred orientation parallel to the vein boundaries.

This reorientation generally produces a well developed microfabric, because coarser and more equant particles (e.g., quartz grains) are rare. The broken surfaces of these dense aggregates reveal globular structures with diameters that range between 20 and $80 \mu \mathrm{m}$ and resemble conchoidal fractures in amorphous or fine-grained isotropic materials (Fig. 3D). Though complete outlines of individual grains are rarely visible, grain sizes of less than $3 \mu \mathrm{m}$ seem to be predominant (Fig. 3E). The fabric change from the sediment to the veins is abrupt, and evidence indicative of in situ deformation of individual grains, such as kinked clay flakes or fitting fragments, is lacking. There was no microscopic evidence of transport of finest-size clay from the sediment into adjacent veins.

\section{MINERALOGY}

The composition of the vein fillings was studied by scanning electron microscopy (SEM) with an energy dispersive EDAX-system for semiquantitative chemical analy- 

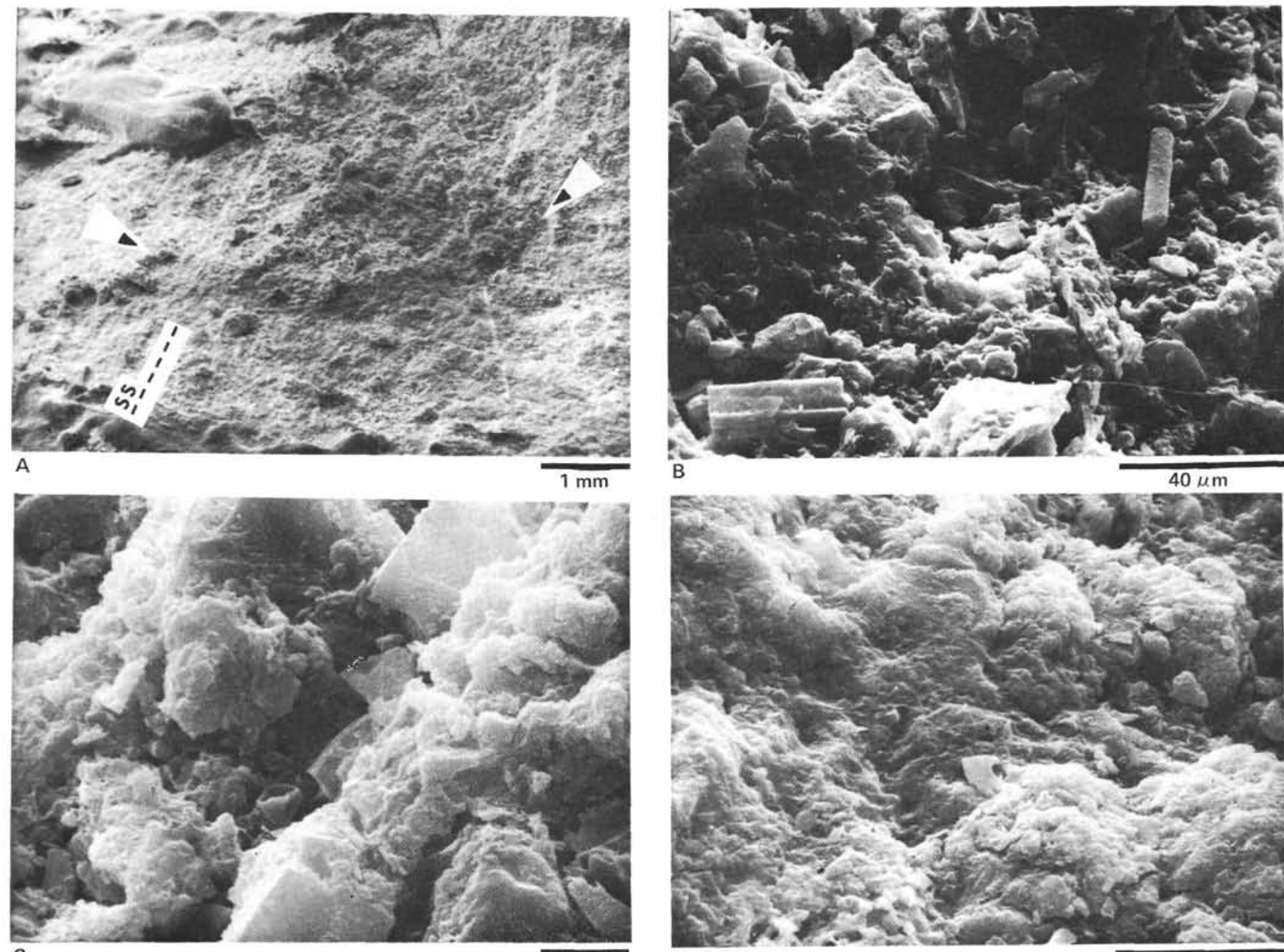

C

$10 \mu \mathrm{m}$
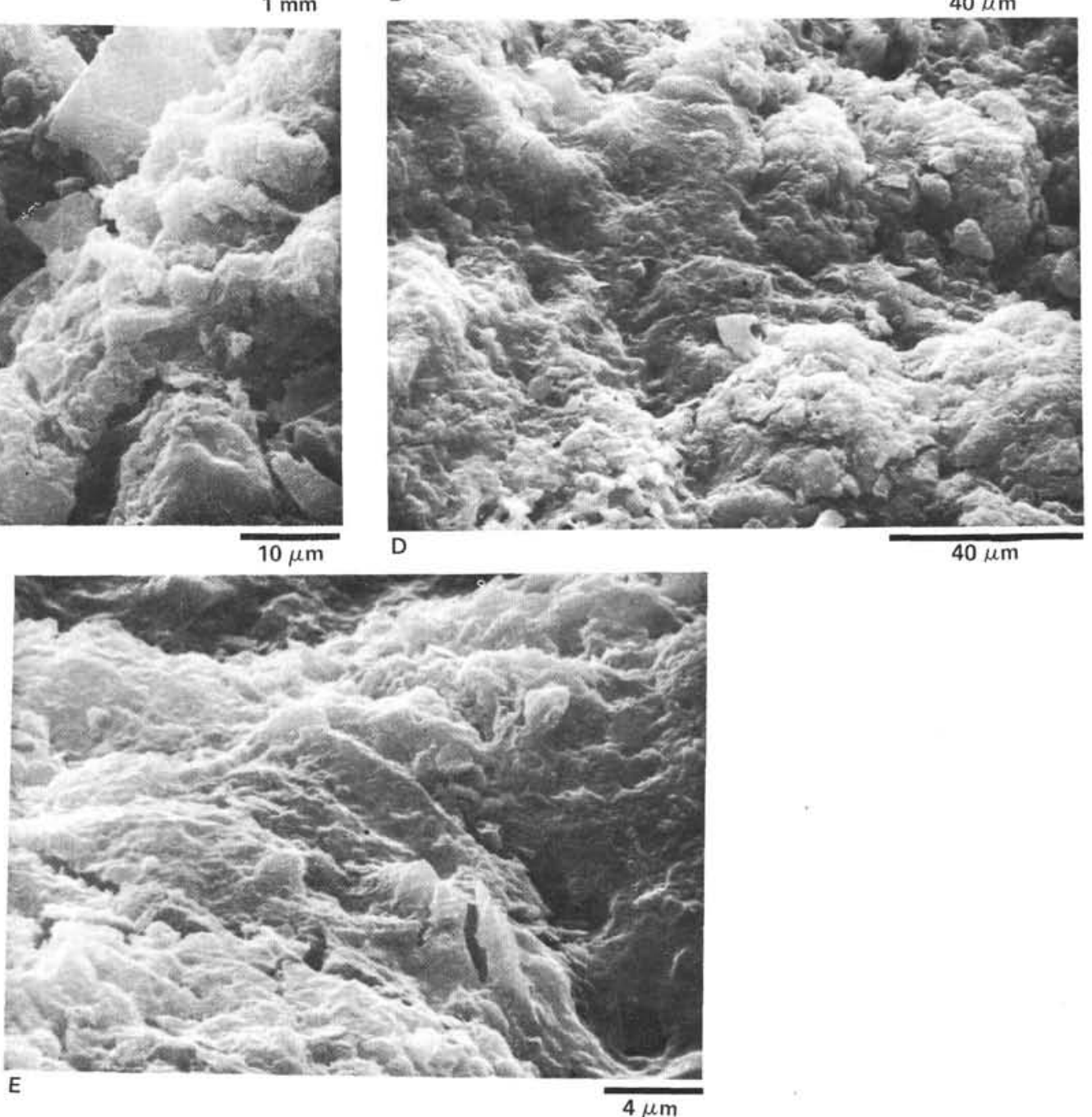

Figure 3. Scanning electron micrographs of vein and sediment on a broken surface. A. Indistinct contours of vein between arrows; ss $=$ weak trace of bedding lamination. B. Microfabric of sediment; porous framework of clay flakes with embedded fossil debris in random orientation. C. Bedding lamination defined by clay-rich layers with strong preferred orientation of individual grains. D. Vein filling of dense clay aggregates with globular break structures; strong preferred orientation of individual grains parallel to the vein boundaries. E. Magnified section of Figure 3D. 
ses. Infrared spectroscopy was employed for mineral identification using the $\mathrm{KBr}$ powder disk method. Because infrared spectroscopy requires a small volume of sample, this method is suitable to study the mineralogy of the veins.

The infrared spectrum of vein material of Sample $569-26-2,50-52 \mathrm{~cm}$ is shown in Figure 4. This spectrum is similar to those of the average $<2-\mu \mathrm{m}$ fraction of mud sediment samples drilled at other DSDP Leg 84 sites offshore Guatemala (Helm, this volume). The main absorbtion bands are O-H (kaolinite), Si-O, O-H-Al, and $\mathrm{Si}-\mathrm{O}-\mathrm{Al}^{\mathrm{VI}}$. These bands can be attributed to a dioctahedral smectite and kaolinite. Moreover the smectitekaolinite ratio is approximately the same as in the $<2$ $\mu \mathrm{m}$ fraction of the sediment of comparable age and depth, according to infrared spectroscopy.

The vein fillings consist of clay minerals, as suggested by SEM. Calcite, however, a widespread mineral in the $<2-\mu \mathrm{m}$ fraction of the adjacent sediment, is completely absent from the veins. The energy dispersive analyses of the vein fillings reveal $\mathrm{Si}$ and $\mathrm{Al}$ as main components (Fig. 5). Minor amounts of $\mathrm{K}, \mathrm{Ca}, \mathrm{Mg}$, and $\mathrm{Na}$ are also present. This composition can be attributed to the prevalence of a dioctahedral smectite. Fe and $\mathrm{S}$ are presumably the result of pyrite, which may be responsible for the dark color of the veins. The color contrast between sediment and veins may also be influenced by their different microfabrics. The distinctly denser veins appear dark within the more porous surrounding sediment. After drying, this contrast diminishes.

Two mechanisms of vein-filling are possible: (1) mechanical filtering from the adjacent sediments, and (2) chemical precipitation from the pore fluid. The absence of calcite and quartz from the veins in contrast to their presence in the adjacent sediments favors the latter mechanism, whereas the difficulty of precipitating kaolinite in these interstitial fluids suggests the first as the more probable model.

\section{KINEMATIC ASPECTS}

A kinematical analysis based on the geometrical relationships between veins, zone boundaries, and sedimentary structures as well as shape characteristics is complicated by the fact that the data have to be obtained from

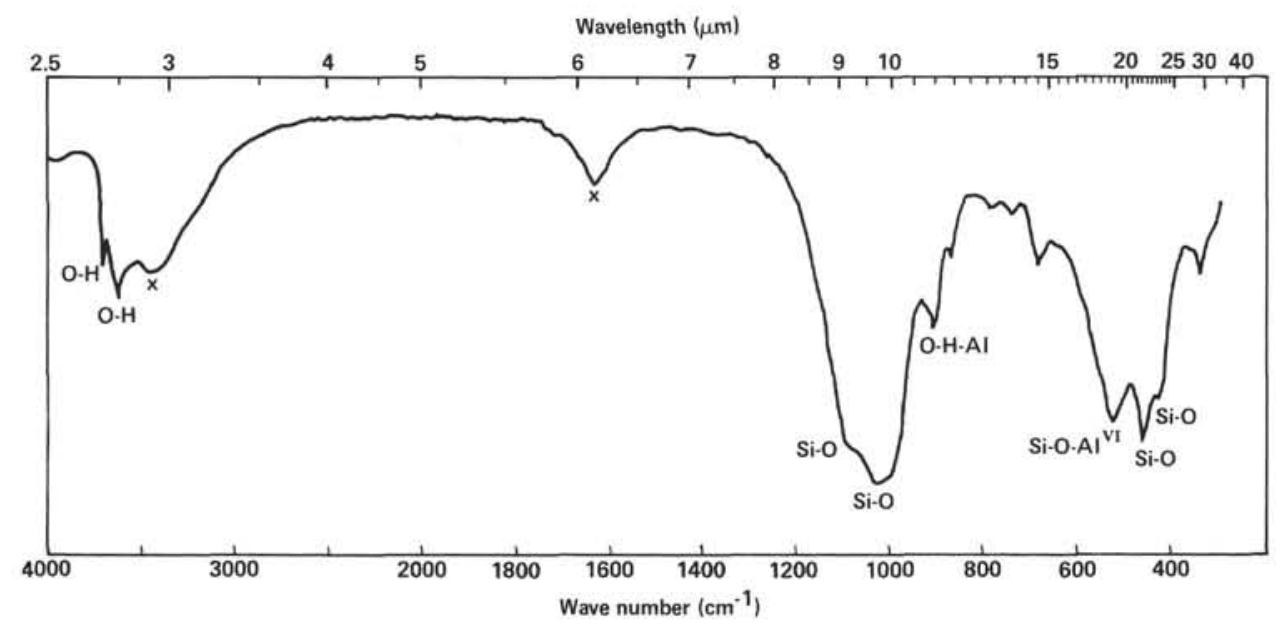

Figure 4. Infrared spectrum of vein-filling material ( $\mathrm{X}$ refers to bands of water molecules).

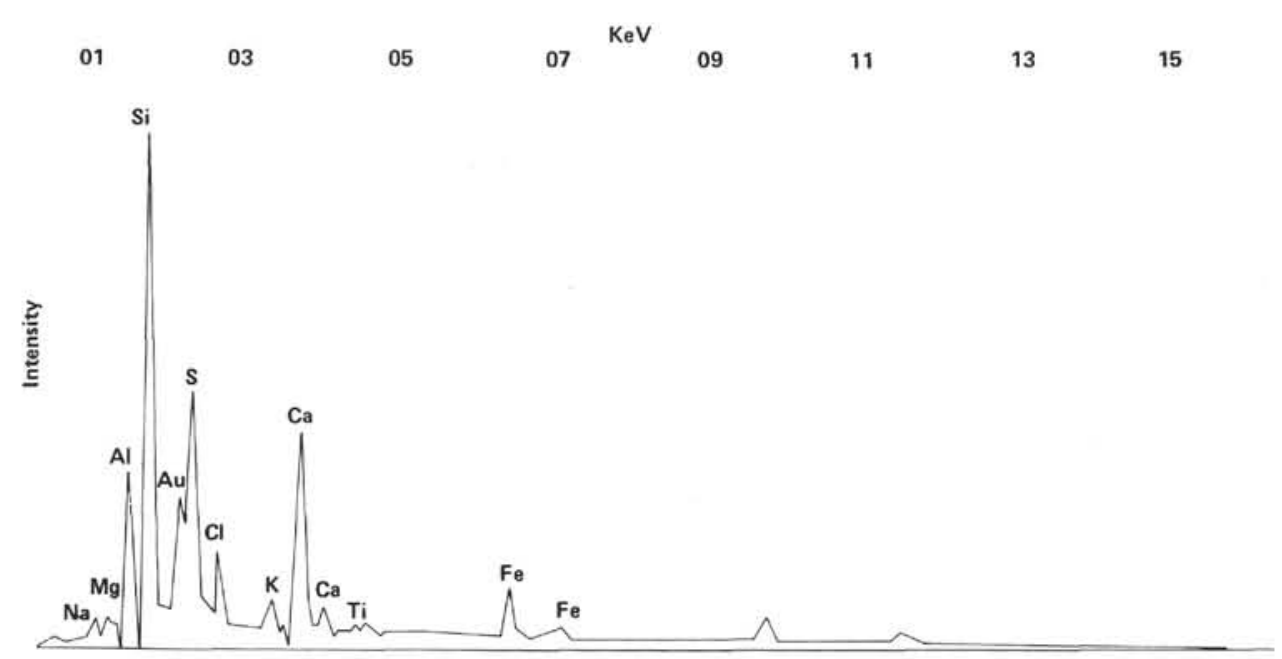

Figure 5. Energy dispersive EDAX spectrogram (Au is the result of surface spattering). 
core cuts intersecting the structures in random orientation. Only apparent dip angles as well as apparent angles of intersection of planar fabric elements can be observed in the core cuts. Disregarding this fact may cause misinterpretations of the principal directions of stress and strain as well as sense of shear. The following considerations are based on the geometrical relationships in approximately true cross sections, that is, core cuts revealing maximum dip angles for the considered elements. Because only samples having a long axis parallel to the core barrel axis were examined, drilling-induced rotation of dip angles with respect to the horizontal can be excluded.

Veins with macroscopic characteristics comparable to those described earlier have been interpreted as extension fractures, for example, extension fractures associated with simple shear zones (Cowan, 1982). En-echelon extension fractures produced by simple shear should originate at angles of about $45^{\circ}$ to the shear zone boundary and rotate during subsequent increments of strain corresponding to the sense of shear to make angles greater than $45^{\circ}$. As new marginal segments form at an angle of $45^{\circ}$, the shape of the growing fractures becomes sigmoidal. The rotation within the flowing matrix is accompanied by shear displacement and further dilatation along the fracture surfaces. Shear zones with this type of extension fracture are well known from lithified rocks exposed on land (e.g., Ramsay and Graham, 1970; Beach, 1975; Roering, 1968).

For our examples, however, this model seems to be unsuitable, because the veins originated at angles distinctly greater than $45^{\circ}$, and shear displacement along the vein boundaries can be detected even for segments that lack any rotational features. These facts suggest that the veins would be better interpreted as extensional shear veins, and later we suggest that they are one type of Riedel shears (Riedel, 1929; Cloos, 1955).

Riedel shear zones can develop as sets of conjugate second-order faults in response to the stresses associated with a first-order simple shear zone. One set develops at a low angle to the shear zone boundary and is called synthetic, because its sense of shear supports the superior shear. The other, antithetic, set makes a high angle with the shear zone boundary and counteracts the superior shear. As an example, the experiments of M. Erkan (personal communication, 1982) are schematically presented in Figure 6, showing the shape and orientation of syn- and antithetic Riedel shears in clay bodies subjected to inhomogeneous simple shear $\left(25^{\circ} \mathrm{C}, 1 \mathrm{~atm}\right.$, shear velocity in the range between 3 and $5 \mathrm{~mm} / \mathrm{min}$.). The experiments clearly demonstrate that the relative quantities of both sets are influenced by the angular relationships between the directions of shear and anisotropy. The weak anisotropy was produced by smoothing of the clay body surface with a spatula, causing a reorientation of clay flakes in such a way that they are inclined to the surface and strike normal to the direction of smoothing. It is obvious that the most striking macroscopic characteristics of the veins described in this study are in good agreement with the antithetic set of these experimentally produced Riedel shears. However, why is the corresponding synthetic set completely absent from the natural shear zones?

The experiments suggest that only the Riedel shears at high angles to the planes of anisotropy are formed. This is well documented by those experiments with the traces of anisotropy parallel or normal to the shear zone boundary, in which only antithetic or synthetic Riedel shears developed, respectively (see Fig. 6, smoothing direction of $90^{\circ}$ or $0^{\circ}$, respectively). Likewise the ratio of syn- to antithetic Riedel shears decreases with decreasing angles between planes of anisotropy and shear zone boundary. A suitable explanation is that the subordinate shear stresses acting at low angles to the planes of anisotropy cause layer-parallel slip rather than fracturing, because the shearing resistance along these planes is comparatively low.

For layer-parallel shear zones with en-echelon veins steeply inclined to the bedding plane (Arthur, von Huene, and Adelseck, 1980; Arthur, Carson, and von Huene,

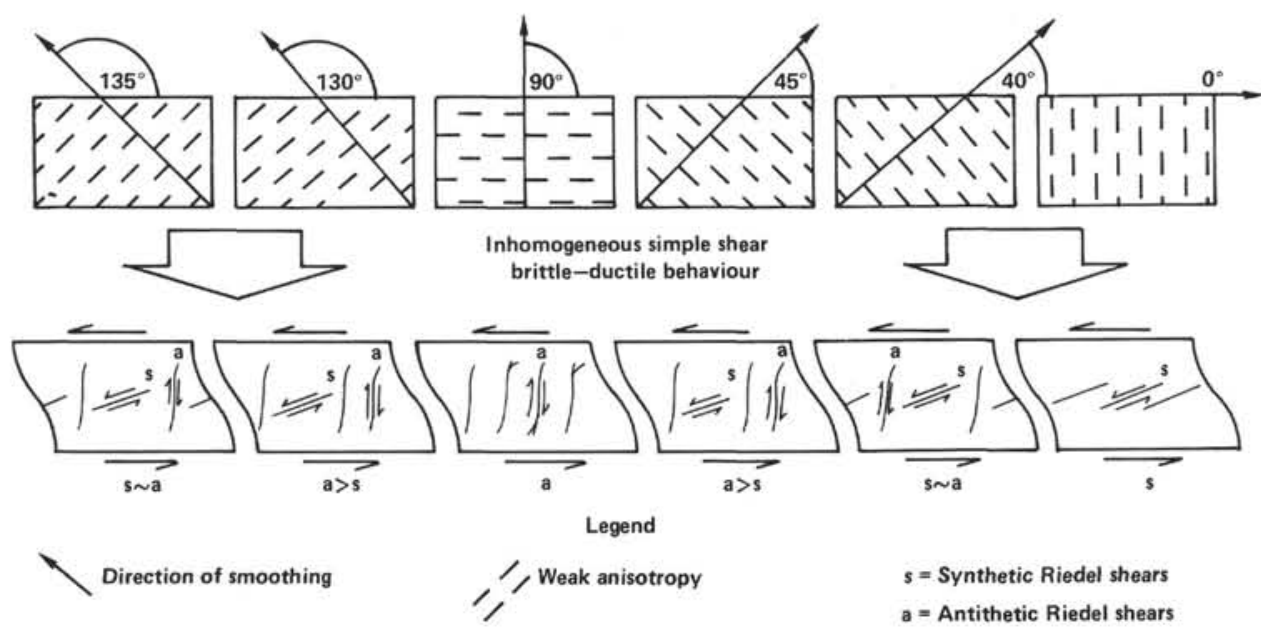

Figure 6. Synthetic and antithetic Riedel shears in weak anisotropic clay bodies subjected to simple shear (with permission, after M. Erkan, personal communication, 1982). 
1980; Cowan, 1982; Dengo, 1982), this model can be easily adopted. The present shear zones from Sites 568 and 569 (200-400 m sub-bottom), however, cannot be directly related to macroscopic bedding because it could not be detected unequivocally on the core photographs. Moreover, in two core cuts the shear zones appear as steeply inclined conjugate sets arranged symmetrically to the core axis, so that even for one set an orientation parallel to bedding seems unlikely. However, as reported by the shipboard party, a steep dip of the bedding planes could be recognized within the fresh samples from these sites. Consequently, as both sets reveal a dip-slip sense of shear, the absence of synthetic Riedel shears could be explained by the model suggested above. This possibility is supported by the microstructure (Fig. 3A), which shows a probable bedding lamination (ss) at a high angle to the vein boundary.

Some of the conjugate shear zones show a polyphase development (Fig. 7), which is schematically illustrated in Figure 8. In this diagram the development starts with a widely spaced first generation of antithetic Riedel shears followed by a second closely spaced generation,

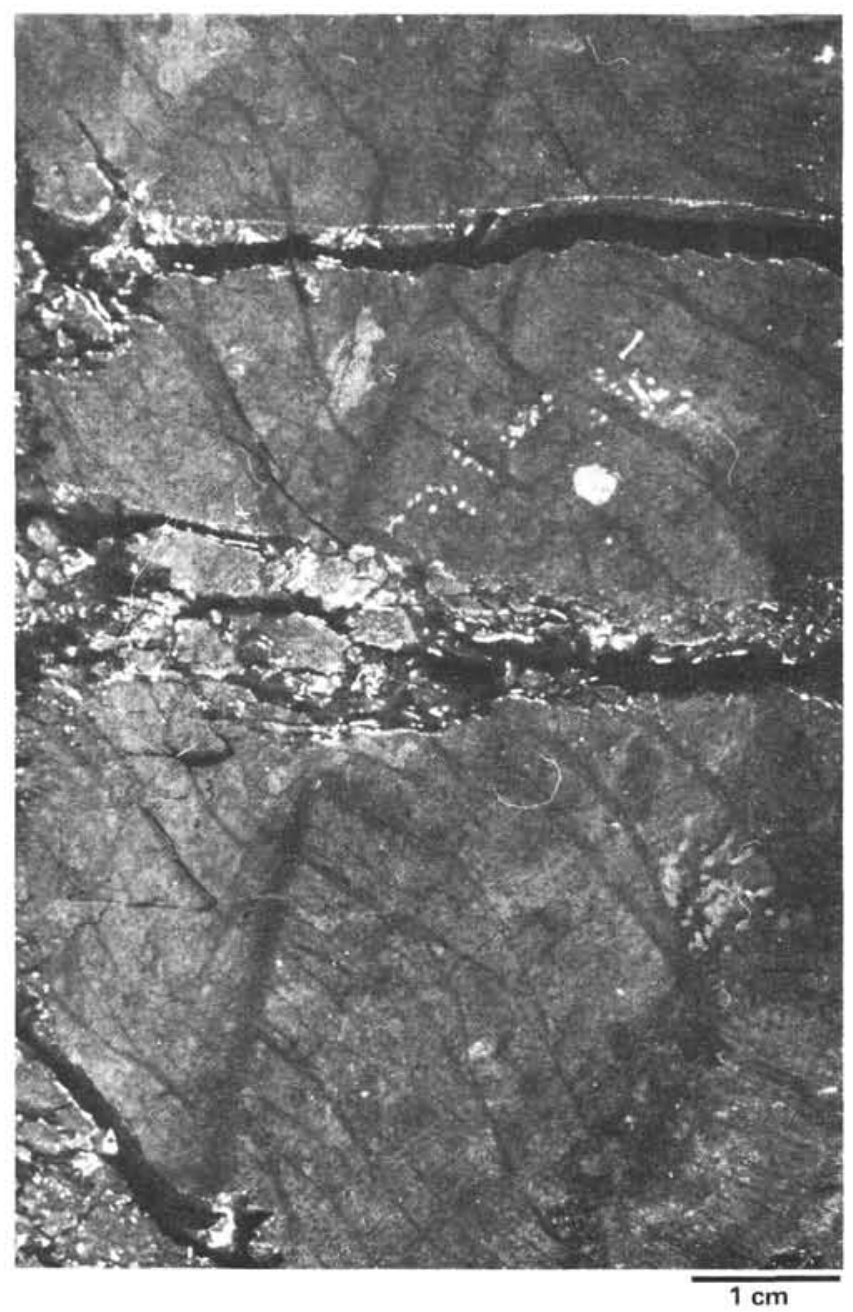

Figure 7. Polyphase shear zone (Sample 569-26-1, 79-87 cm); for explanation see Figure 8. and ends with a single shear fracture parallel to the shear zone boundary, which reflects a trend from brittle-ductile to brittle behavior (e.g., Ramsay, 1980). This trend could be explained by different mechanisms, for example, strain-induced increase of pore pressures lowering the shearing resistance of clay matrix or synkinematic lithification.

The sense of displacement of both shear zones of a conjugate set corresponds to normal faults, being almost symmetrically inclined about 50 to $70^{\circ}$ to the core axis. Accordingly, the direction of maximum finite shortening should be subvertical. Moreover, a coaxial progressive deformation can be assumed from the symmetrical arrangement of veins in both zones of a conjugated set and from the fact that successive generations (evident from displacement of veins) of adjacent shear zones originated in parallel directions. Thus the direction of maximum compressive stress $\left(\sigma_{1}\right)$ could be related to gravitational forces, that is, overburden pressure. Accordingly, gently dipping stratabound shear zones, as observed by Cowan (1982), for example, could result from gravitational downslope movement associated with bedding parallel shear.

Another possible model explaining both conjugate and strata-bound shear zones is the slight buckling of a sedimentary unit caused by folding or dragging along major thrust faults or shear zones, for instance, in response to regional-scale slumping or subduction processes (Fig. 9). In sequences exhibiting distinct bedding planes, bedding-parallel shear stresses associated with flexural slip would produce strata-bound shear zones with antithetic Riedel shears within the less competent strata. In contrast, sediments lacking distinct bedding planes are unfavored for flexural slip and reveal a more isotropic behavior. Thus conjugate shear zones develop that are directly controlled by the principal directions of the major stress field. In the upper part of the buckling body (outer arc), $\sigma_{1}$ is directed normal and $\sigma_{3}$ parallel to the surface. The corresponding conjugate shear zones should develop at a low angle to $\sigma_{1}$. In the lower part of the buckling body (inner arc), $\sigma_{1}$ and $\sigma_{3}$ exchange their directions; hence, gently dipping conjugate shear zones should be expected.

\section{SUMMARY}

Zones of dark-colored en-echelon veins are a common feature in slope sediments of DSDP Sites 568 and 569 off Guatemala. The veins are filled with compact aggregates of fine-grained clay flakes $(\leq 3 \mu \mathrm{m})$ that have a strong preferred orientation parallel to the vein boundaries. The composition is similar to the phyllosilicates of the same size in the adjacent sediment (kaolinite, smectite). The veins mark brittle-ductile shear zones that may develop either parallel to the bedding or, if distinct bedding planes are absent, as conjugate sets.

The individual veins show all characteristics of antithetic Riedel shears and hence should not be interpreted as extension fractures, although a dilatational component of displacement is evident from the vein filling. Synthetic Riedel shears, which should originate at a low 


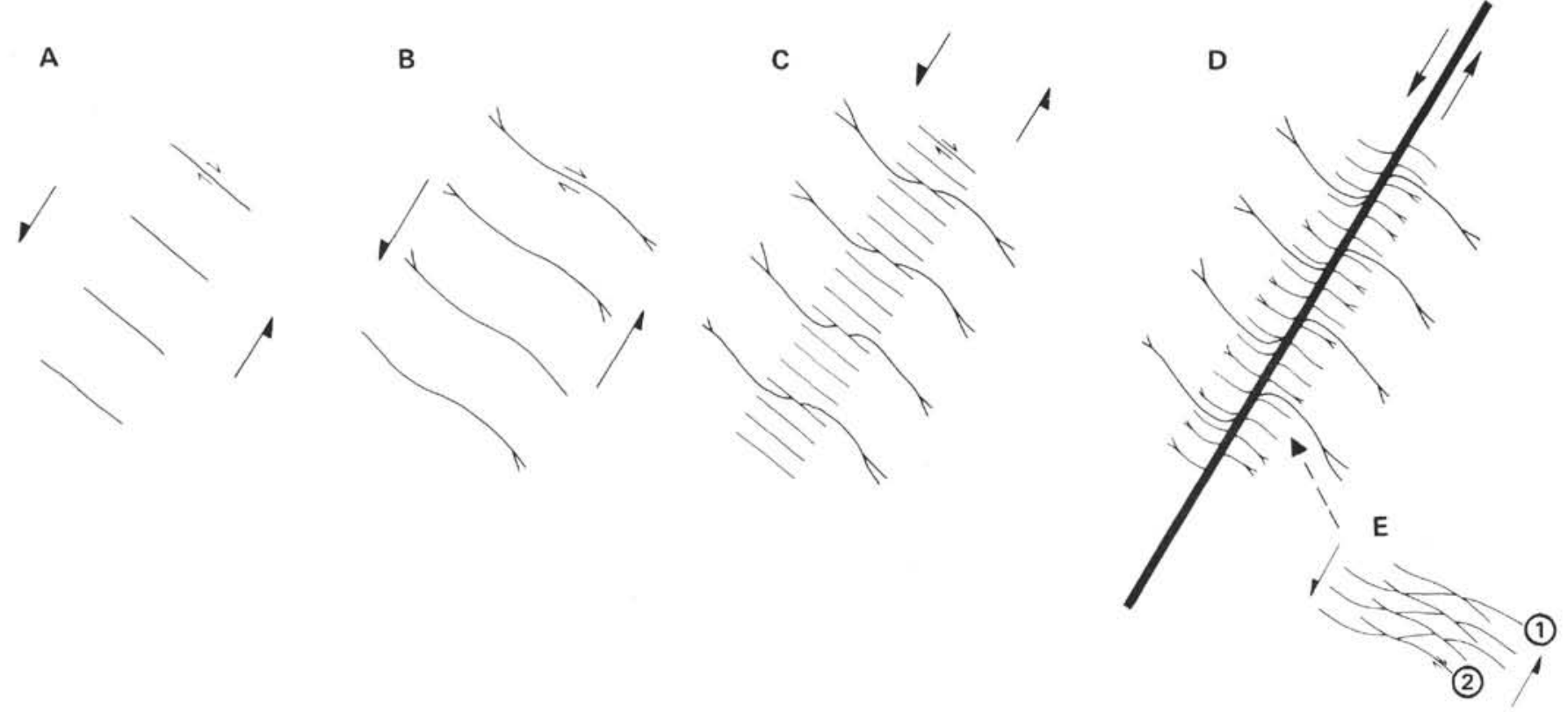

Figure 8. Polyphase shear zone development indicating a change from brittle-ductile to brittle behavior. A. First generation of widely spaced antithetic Riedel shears. B. Lateral growth with branching of the ends and rotation of the central segments. C. Second generation of narrowly spaced antithetic Riedel shears displacing first-generation fractures. D. Main shear fracture parallel to the shear zone boundary; displacement and dragging of preceding Riedel shears. E. Rhomb-shaped fracture pattern resulting from interference of two successive narrowly spaced generations of antithetic Riedel shears (1 and 2).

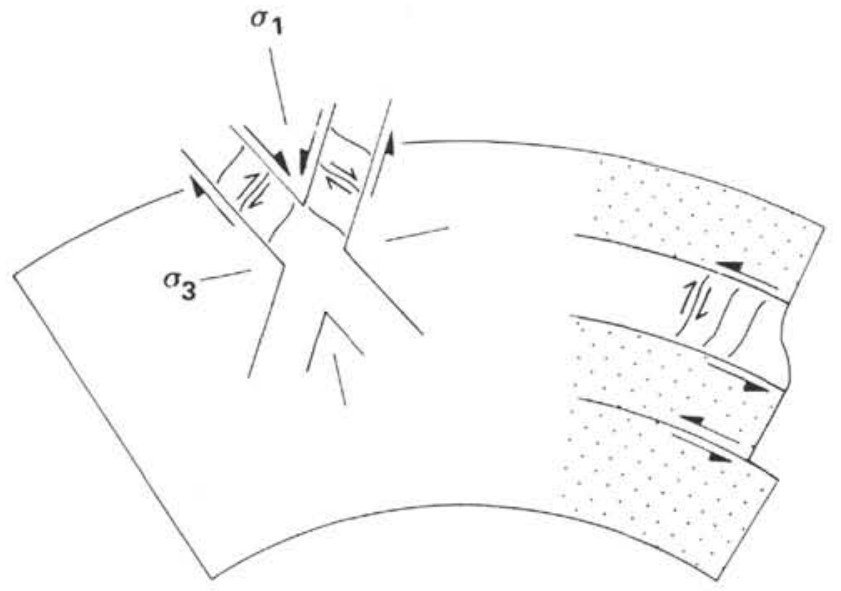

Figure 9. Model explaining both conjugate and strata-bound shear zones with antithetic Riedel shears by buckling of a sedimentary unit. Buckling may be related to folding or dragging along major thrust planes (for further explanation see text).

angle to the shear zone boundaries, are absent within all available samples and have not been described by other authors. The synthetic set probably remains inactive if the required strain can be achieved by other mechanisms, for example, slip or bedding laminae in stratabound shear zones or even in conjugate sets, if they are in appropriate orientation to the bedding.

Strata-bound shear zones may be related to bedding parallel shear stresses resulting from gravitational downslope sliding or flexural slip associated with incipient folding or dragging in the vicinity of major faults. For the conjugate shear zones observed at DSDP Sites 568 and 569 between 200 and $400 \mathrm{~m}$ sub-bottom, the rhom- bic symmetry as well as the parallel orientation of successive generations indicate a coaxial progressive deformation with a subvertical direction of maximum finite shortening. These could be related to overburden pressure, provided the sediment is allowed to extend laterally. The shear zones could also be formed on the outer arc of a sedimentary unit that is buckled by subduction mechanisms or regional scale slumping.

\section{ACKNOWLEDGMENTS}

We gratefully thank Prof. H. Füchtbauer for critically reading the manuscript and Prof. R. Hoeppener for helpful discussions. Thanks are due to $M$. Erkan for providing experimental data and K. Strehlau who drafted the figures. We also acknowledge Tim Byrne at Brown University and Darrel Cowan at University of Washington for their reviews. This investigation was supported by the Deutsche Forschungsgemeinschaft (project no. Fu 66/27).

\section{REFERENCES}

Arthur, M. A., Carson, B., and von Huene, R., 1980. Initial tectonic deformation of hemipelagic sediment at the leading edge of the Japan convergent margin. In Scientific Party, Init. Repts. DSDP, 56, 57, Pt. 1: Washington (U.S. Govt. Printing Office), 569-613.

Arthur, M. A., von Huene, R., and Adelseck, C. G., 1980. Sedimentary evolution of the Japan fore-arc region off Northern Honshu, Legs 56 and 57, Deep Sea Drilling Project. In Scientific Party, Init. Repts. DSDP, 56, 57, Pt. 1: Washington (U.S. Govt. Printing Office), $521-568$.

Beach, A., 1975. The geometry of en-echelon vein arrays. Tectonophysics, 28:245-263.

Cowan, D. S., 1982. Origin of "vein structures" in slope sediments on the inner slope of the Middle America trench off Guatemala. In Aubouin, J., von Huene, R., et al., Init. Repts. DSDP, 67: Washington (U.S. Govt. Printing Office), 645-650.

Cloos, E., 1955. Experimental analysis of fracture patterns. Geol. Soc. Am. Bull., 66:241-256.

Dengo, C. A., 1982. A structural analysis of cores from the Leg 67 transect across the Middle America Trench - offshore Guatemala. 
In Aubouin, J., von Huene, R., et al., Init. Repts. DSDP, 67: Washington (U.S. Govt. Printing Office), 651-666.

Ramsay, J. G., 1980. Shear zone geometry: a review. J. Struct. Geol., 2:83-99.

Ramsay, J. G., and Graham, R. H., 1970. Strain variation in shear belts. Can. J. Earth Sci., 7:786-813.

Riedel, W., 1929. Zur Mechanik geologischer Brucherscheinungen. Centralbl. f. Min., Geol. u. Pal., 1929B, 354-368.
Roering, C., 1968. The geometrical significance of natural en-echelon crack arrays. Tectonophysics, 5:107-123.

Scientific Party, 1980. Init. Repts. DSDP, 56, 57, Pt. 1: Washington (U.S. Govt Printing Office).

Date of Initial Receipt: 9 January 1984

Date of Acceptance: 7 March 1984 